\title{
VISUALIZATION OF AIRWAY
}

\author{
Kamil Toker \\ Department of Anesthesiology and Reanimation, Bahcesehir University School of Medicine, \\ Istanbul / Turkey
}

\begin{abstract}
SUMMARY - The author provides an overview of the history of optical instruments for airway management in anesthesiology. It systematically demonstrates the development of laryngoscope down to the present time when video laryngoscope has been introduced in clinical practice.
\end{abstract}

Key words: Laryngoscope; Video laryngoscope; History; Fiberscope

Humans have by nature been always very keen to look inside body cavities. This concern is as old as our existence. The earliest descriptions of body cavity were those from the Kos school led by Hippocrates (460$375 \mathrm{BC})$. He described a rectal speculum similar to the instruments used today. Similar instruments were found in the ruins of Pompei ${ }^{1}$.

Airway anatomy, because of breathing and phonation, was one of the body cavities of special interest. Access to the airway also dates back to Hippocrates. He advised introduction of a pipe into the larynx of a suffocating patient. A silver pipe was used for the same purpose by Avicenna of Bukhara (1000 AD). Andreas Vaselius (1514-1564), a famous anatomist, introduced a reed into the airway of experimental animal with open chest and to inflate the lungs returned with the stopped heart. He mistakenly assumed the trachea to be part of the circulatory system.

Although instruments for the inspection of body cavities such as the mouth, nose, ear, vagina, rectum and urethra have been in use for ages, the larynx could be only insufficiently inspected by forcible depression of the tongue with a 'Glossokatochon' spatula ${ }^{2}$.

It became possible to look into the trachea after the invention of instruments for inspection, along with

Correspondence to: Prof. Kamil Toker, Bahcesehir University School of Medicine Department of Anesthesiology and Reanimation, Istanbul, Turkey

E-mail: tokerkamil@yahoo.com; kamiltoker@gmail.com

Received March 11, 2015, accepted September 14, 2015 suitable light sources and anesthesia. Visualization of the airway, particularly larynx, was needed first for surgical aspects. Direct and indirect methods have been used to visualize the airway depending on the resources. It started with indirect methods, followed by direct methods. It seems that with the improvement of technology, indirect visualization has become popular again.

The term laryngoscopy referred to mirrored or indirect examination of the larynx at the beginning and throughout the $19^{\text {th }}$ century, and was widely used for surgical aspects ${ }^{3}$. In 1829, Benjamin Guy Babington, a medical student, invented a device like chopsticks with spatula on the ends, called 'glottiscope'. Sunlight was used for illumination and viewing the glottis. It is not known whether or not he could see the glottis, but later his device was called laryngoscope by Thomas Hodgkins. Babington made famous and valuable contribution to medicine, such as the first description of hereditary hemorrhagic telangiectasia, but he never published anything in the field of laryngology $y^{4,5}$.

In 1852, Horace Green, a specialist in Manhattan, reported first direct laryngoscopy, which he used to perform transoral removal of a neoplasm from the laryngeal ventricle in an 11-year-old girl ${ }^{3,6}$.

Although some experiments were done to inspect larynx with the help of mirrors, Manuel Garcia, a singing teacher from London, was the first to observe his own larynx and vocal cords with the help of a dental mirror, laryngeal mirror, using sunlight reflected by another mirror in $1854^{2}$. 
Almost at the same time, in 1856 in Vienna, Ludwig Türck, a laryngologist, performed experiments with a similar device, which he borrowed from Czermak, a physiologist from Budapest. Czermak reported his results before Türck, which resulted in their fight over the rights of priority ${ }^{2}$.

Afterwards, some physicians tried to diagnose and treat laryngeal diseases, but one of the major problems was direct and reverse view of the image.

The first suitable light source to inspect body cavities was invented by Philipp Bozzini, a general practitioner from Frankfurt, at the beginning of the $19^{\text {th }}$ century. Another suitable alternative successor light source was invented by Desormeaux in 1853. The term 'endoscope' was introduced by Desormeaux for his instrument to inspect body cavities. It was first used for esophagoscopy and gastroscopy. Subsequently, the 'endoscope' was modified by many specialists ${ }^{2}$.

Albert Kirstein from Berlin started to intubate larynx with esophagoscope. His first experience was inadvertent insertion of the esophagoscope in 1894, then he improved the eosophagoscope to a rigid laryngoscope with light and began systematic direct inspection of the larynx. He called the instrument 'autoscope', meaning "directly without help of a mirror" in Greek ${ }^{1,2,11}$. The autoscope consisted of a lamp within the handle focused on a lens and redirected through the scope by a prism?

Maceven, a British surgeon, tried blind, digital intubation on cadavers first and used the technique on a real patient for composite resection in $1878^{7}$.

In the 1870s, Joseph O'Dwyer saved lives of hundreds of children that were suffocating from diphtheria with the instruments he developed to intubate the trachea ${ }^{2}$. Hans Kuhn modified O'Dwyer's instruments and developed a new one, but it was only for blind intubation too.

Chevalier Jackson modified the autoscope providing distal illumination and developed his first direct laryngoscope in $1903^{3,5}$.

Many designs of laryngoscope blades were developed until the 1940s, e.g., Lundy, Guedel, Wisconsin, Searle, etc., but no information regarding laryngoscope blades had not yet been published ${ }^{5}$.

Robert Miller introduced a new rigid laryngoscope with a longer blade in 1941 and published it in the journal Anesthesiology. It was the same as the current blade named after him ${ }^{5,78}$.

In 1943, Robert Macintosh designed a new curved blade which could elevate the epiglottis. He suggested that less contact with the epiglottis would cause less stimulation and provide more space for endotracheal tube insertion'. Both Miller and Macintosh blades still dominate in the field of direct laryngoscopy, but, there have been developments of new laryngoscopes as both failed to intubate a significant number of $\mathrm{pa}-$ tients because of poor view. One of the latest is McCoy, an articulating laryngoscope designed in 1993, which facilitates pressing the base of the tongue and elevate the epiglottis ${ }^{7}$.

In 1897, Gustav Killian, a German physician, performed the first rigid bronchoscopy, which remained the only technique available until the late 1970s, when the fiber optic technology emerged.

The development of fiber optic is almost two centuries old. In the 1840s, Daniel Colladon and Jacques Babinet from Paris proposed that light could be guided through refraction. In 1870, John Tyndall used jet of water that flowed from one container to another to demonstrate that light used internal reflexion in fiber optic. The cornerstone of modern fiber optic is the invention of a system of light pipe lined with highly reflective coating by William Wheeler in 1880. Eight years later, Roth and Reuss proposed the use of fiber optic to visualize body cavity through the fiber optic system and demonstrated illumination of body cavity by a bent glass rod through the source of light. The revolution came in the 1950s, when Brian O'Brien made the first fiberscope in the US and Nrinder Kapany first used the term 'fiber-optic' in London in 1956.

The first fiber optic endoscope was invented by Fernando Alves Martins in Portugal in 1963. In 1966, Shigeto Ikeda from Japan invented the first flexible bronchoscope. The first flexible bronchoscope was made up with fiber optic bundles requiring external light source.

In 1967, Murphy used fiber optic choledochoscope to perform nasal intubation under general anesthe$\mathrm{sia}^{10}$. After Murphy's success, flexible fiber optic technology was used to assist endotracheal intubation.

In 1972, Claire Stiles reported the use of fiber optic intubation in 100 patients $^{11}$. Thereafter, the use of 
this device was spread and additional similar reports soon followed. In the late 1970s, Katz and Berci introduced a straight rigid endoscope used as a tracheal tube stylet during intubation, which they called 'optical stylet'. It was good for teaching purposes, but its straight design limited its use for difficult airway management. Optical stylets with fixed curve, malleable or semi malleable and/or formable tip have existed down to the present. Some of them are still in use and some have commercially disappeared ${ }^{12}$.

The development of rigid fiber optic laryngoscopes and/or optical stylets has provided some benefits for the intubators, such as an eyepiece attachable to the optional video camera. They also provide a non-lineof sight view and use of dedicated monitor with a video camera attached. This configuration has embodied the concept of video laryngoscopy.

In 2001, John Pacey, a Canadian surgeon, was the first who embedded a video chip into a modified laryngoscope, Glidescope video laryngoscope. One year later, Kaplan and Berci incorporated a special light source, video processor and monitor into the Macintosh laryngoscope, Storz Berci-Kaplan DCI Video Macintosh. Thereafter, several products with different capabilities have been introduced to visualize the airway to date ${ }^{13}$.

It seems that advances in technology along with science will provide new developments in this area. Wireless and remote image transmission can be a new step in the future. It is not easy to imagine new developments at long term.

\section{References}

1. Lau WY, Leow CK, Li AKC. History of endoscopic and laparoscopic surgery. World J Surg. 1997;21:444-53.

2. Becker HD. A short history of bronchoscopy. In: Ernst A, editor. Introduction to Bronchoscopy. Cambridge: Cambridge University Press, 2009:1-10.

3. Zeilets SM. Chevalier Jackson's contributions to direct laryngoscope. J Voice. 1998;12(1):1-6. doi:10.1016/S08921997(98)80069-6

4. Koltai PJ, Nixon RE. The story of the laryngoscope. Ear Nose Throat. 1989;68:494-502.

5. Burkle CM, Zepeda FA, Bacon DR, Rose SH. A historical perspective on use of the laryngoscope as a tool in anesthesiology. Anesthesiology. 2004;100:1003-6.

6. Greenland KB, Eley V, Edwards MJ, Allen P, Irwin MG. The origins of the sniffing position and The Three Axes Alignment Theory for direct laryngoscopy. Anesth Intensive Care. 2008;36(Suppl 1);23-7.

7. Cooper RM. Laryngoscopy. Its past and future. Can J Anesth. 2004;51(6):R1-R5.

8. Miller RA. A new laryngoscope. Anesthesiology. 1941;2:31720. doi: 10.1007/BF03018336

9. MacIntosh RR. A new laryngoscope. Lancet. 1943;1:205.

10. Murphy P. A fibre-optic endoscope used for nasal intubation. Anaesthesia. 1967;22:489-91. doi: 10.1111/j.13652044.2010.06535.x

11. Stiles CM, Stiles QR, Denson JS. A flexible fiber optic laryngoscope. JAMA. 1972;221(11):1246-7.

12. Liem EB, Bjoraker DG. New options for airway management: intubating fibreoptic stylets. Br J Anaesth. 2003;91(3):40818. doi: 10.1093/bja/aeg011

13. Cooper RM. Transitioning from direct to video laryngoscopy. Anesthesiology News Guide to Airway Management 2009;25-8.

Sažetak

\section{VISUALIZIRANJE DIŠNOGA PUTA}

\section{K. Toker}

Autor u svom radu daje pregled razvoja kroz povijest optičkih instrumenata za zbrinjavanje dišnoga puta u anesteziologiji. Sistematizirano prikazuje razvoj laringoskopa sve do današnjih dana kada se u kliničku praksu uvodi video laringoskop.

Ključne riječi: Laringoskopi-povijest; Fiberoptička tehnologija- povijest; Video snimanje; 